Internat. J. Math. \& Math. Sci.

Vol. 23, No. 3 (2000) 205-210

S0161171200001599

(C) Hindawi Publishing Corp.

\title{
RELATED FIXED POINTS FOR SET VALUED MAPPINGS ON TWO METRIC SPACES
}

\author{
BRIAN FISHER and DURAN TÜRKOḠLU
}

(Received 30 July 1998)

\begin{abstract}
Some related fixed points theorems for set valued mappings on two complete and compact metric spaces are proved.

Keywords and phrases. Set valued mapping, complete metric space, compact metric space, fixed point.
\end{abstract}

2000 Mathematics Subject Classification. Primary 47H10; Secondary 54H25.

We let $(X, d)$ be a complete metric space and let $B(X)$ be the set of all nonempty subsets of $X$. As in [1, 2], we define the function $\delta(A, B)$ with $A$ and $B$ in $B(X)$ by $\delta(A, B)=$ $\sup \{d(a, b): a \in A, b \in B\}$. If $A$ consists of a single point $a$ we write $\delta(A, B)=\delta(a, B)$. If $B$ also consists of single point $b$, we write $\delta(A, B)=\delta(a, B)=\delta(a, b)=d(a, b)$. It follows immediately that $\delta(A, B)=\delta(B, A) \geq 0$, and $\delta(A, B) \leq \delta(A, C)+\delta(C, B)$ for all $A, B$ in $B(X)$.

Now if $\left\{A_{n}: n=1,2, \ldots\right\}$ is a sequence of sets in $B(X)$, we say that it converges to the set $A$ in $B(X)$ if

(i) each point $a \in A$ is the limit of some convergent sequence $\left\{a_{n} \in A_{n}: n=\right.$ $1,2, \ldots\}$,

(ii) for arbitrary $\epsilon>0$, there exists an integer $N$ such that $A_{n} \subset A_{\epsilon}$ for $n>N$, where $A_{\epsilon}$ is the union of all open spheres with centers in $A$ and radius $\epsilon$.

The set $A$ is then said to be the limit of the sequence $\left\{A_{n}\right\}$.

The following lemma was proved [1].

LEMMA. If $\left\{A_{n}\right\}$ and $\left\{B_{n}\right\}$ are sequences of bounded subsets of a complete metric space $(X, d)$ which converge to the bounded subsets $A$ and $B$, respectively, then the sequence $\left\{\delta\left(A_{n}, B_{n}\right)\right\}$ converges to $\delta(A, B)$.

Now, let $F$ be a mapping of $X$ into $B(X)$. We say that the mapping $F$ is continuous at a point $X$ if whenever $\left\{x_{n}\right\}$ is a sequence of points in $X$ converging to $x$, the sequence $\left\{F x_{n}\right\}$ in $B(X)$ converges to $F x$ in $B(X)$. We say that $F$ is continuous mapping of $X$ into $B(X)$ if $F$ is continuous at each point $x$ in $X$. We say that a point $z$ in $X$ is a fixed point of $F$ if $z$ is in $F z$. If $A$ is in $B(X)$, we define the set $F A=\bigcup_{a \in A} F a$.

THEOREM 1. Let $\left(X, d_{1}\right)$ and $\left(Y, d_{2}\right)$ be complete metrics spaces, let $F$ be mapping of $X$ into $B(Y)$ and let $G$ be mapping of $Y$ into $B(X)$ satisfying the inequalities

$$
\delta_{1}\left(G F x, G F x^{\prime}\right) \leq c \max \left\{d_{1}\left(x, x^{\prime}\right), \delta_{1}(x, G F x), \delta_{1}\left(x^{\prime}, G F x^{\prime}\right), \delta_{2}\left(F x, F x^{\prime}\right)\right\},
$$




$$
\delta_{2}\left(F G y, F G y^{\prime}\right) \leq c \max \left\{d_{2}\left(y, y^{\prime}\right), \delta_{2}(y, F G y), \delta_{1}\left(y^{\prime}, F G y^{\prime}\right), \delta_{1}\left(G y, G y^{\prime}\right)\right\}
$$

for all $x, x^{\prime}$ in $X$ and $y, y^{\prime}$, where $0 \leq c<1$. If $F$ is continuous, then $G F$ has a unique fixed point $z$ in $X$ and $F G$ has a unique fixed point $w$ in $Y$.

Proof. Let $x_{1}$ be an arbitrary point in $X$. Define sequences $\left\{x_{n}\right\}$ and $\left\{y_{n}\right\}$ in $X$ and $Y$, respectively, as follows. Choose a point $y_{1}$ in $F x_{1}$ and then a point $x_{2}$ in $G y_{1}$. In general, having chosen $x_{n}$ in $X$ and $y_{n}$ in $Y$ choose $x_{n+1}$ in $G y_{n}$ and then $y_{n+1}$ in $F x_{n+1}$ for $n=1,2, \ldots$ Then,

$$
\begin{aligned}
d_{1}\left(x_{n+1}, x_{n+2}\right) \leq & \delta_{1}\left(G F x_{n}, G F x_{n+1}\right) \\
\leq & c \max \left\{d_{1}\left(x_{n}, x_{n+1}\right), \delta_{1}\left(x_{n}, G F x_{n}\right), \delta_{1}\left(x_{n+1}, G F x_{n}\right),\right. \\
& \left.\delta_{1}\left(x_{n+1}, G F x_{n+1}\right), \delta_{2}\left(F x_{n}, F x_{n+1}\right)\right\} \\
\leq & c \max \left\{\delta_{1}\left(G F x_{n-1}, G F x_{n}\right), \delta_{1}\left(G F x_{n}, G F x_{n+1}\right), \delta_{2}\left(F x_{n}, F x_{n+1}\right)\right\} \\
= & c \max \left\{\delta_{1}\left(G F x_{n-1}, G F x_{n}\right), \delta_{2}\left(F x_{n}, F x_{n+1}\right)\right\}
\end{aligned}
$$

and, similarly,

$$
\begin{aligned}
d_{2}\left(y_{n+1}, y_{n+2}\right) & \leq \delta_{2}\left(F G y_{n}, G F y_{n+1}\right) \\
& \leq c \max \left\{\delta_{2}\left(F G y_{n-1}, F G y_{n}\right), \delta_{1}\left(G y_{n}, G y_{n+1}\right)\right\} .
\end{aligned}
$$

It follow that, for $r=1,2, \ldots$,

$$
\begin{aligned}
d_{1}\left(x_{n+1}, x_{n+r+1}\right) & \leq \delta_{1}\left(G F x_{n}, G F x_{n+r}\right) \\
& \leq \delta_{1}\left(G F x_{n}, G F x_{n+1}\right)+\cdots+\delta_{1}\left(G F x_{n+r-1}, G F x_{n+r}\right) \\
& \leq\left(c^{n}+c^{n+1}+\cdots+c^{n+r-1}\right) \delta_{1}\left(x_{1}, G F x_{1}\right)<\epsilon
\end{aligned}
$$

for $n$ greater than some $N$, since $c<1$. The sequence $\left\{x_{n}\right\}$ is, therefore, a Cauchy sequence in the complete metric space $X$ and so has a limit $z$ in $X$. Similarly, the sequence $\left\{y_{n}\right\}$ is a sequence in complete metric space $Y$ and so has a limit $w$ in $Y$.

Further

$$
\begin{aligned}
\delta_{1}\left(z, G F x_{n}\right) & \leq d_{1}\left(z, x_{m+1}\right)+\delta_{1}\left(x_{m+1}, G F x_{n}\right) \\
& \leq d_{1}\left(z, x_{m+1}\right)+\delta_{1}\left(G F x_{m}, G F x_{n}\right),
\end{aligned}
$$

since $x_{m+1} \in G F x_{m}$. Thus, on using inequality (5), we have

$$
\delta_{1}\left(z, G F x_{n}\right) \leq d_{1}\left(z, x_{m+1}\right)+\epsilon
$$

for $m, n \geq N$. Letting $m$ tends to infinity it follows that

$$
\delta_{1}\left(z, G F x_{n}\right)<\epsilon
$$

for $n>N$ and so

$$
\lim _{n \rightarrow \infty} G F x_{n}=\{z\}
$$

since $\epsilon$ is arbitrary. Similarly,

$$
\lim _{n \rightarrow \infty} F G y_{n}=\{w\}=\lim _{n \rightarrow \infty} F x_{n}
$$


since $x_{n+1}$ is in $G y_{n}$. Using the continuity of $F$, we see that

$$
\lim _{n \rightarrow \infty} F x_{n}=F z=\{w\} .
$$

Using inequality (1), we now have

$$
\delta_{1}\left(G F x_{n}, G F z\right) \leq c \max \left\{d_{1}\left(x_{n}, z\right), \delta_{1}\left(x_{n}, G F x_{n}\right), \delta_{1}(z, G F z), \delta_{2}\left(F z, F x_{n}\right)\right\} .
$$

Letting $n$ tends to infinity and using (9) and (11), we have

$$
\delta_{1}(z, G F z) \leq c \delta_{1}(z, G F z) .
$$

Since $c<1, \delta_{1}(z, G F z)=0$ and, so, we must have $G F z=\{z\}$, proving that $z$ is a fixed point of $G F$.

Further, using (11), we have

$$
F G w=F G F z=F z=w,
$$

proving that $w$ is a fixed point of $F G$.

Now suppose that $G F$ has a second fixed point $z^{\prime}$. Then using inequalities (1) and (2), we have

$$
\begin{aligned}
\delta_{1}\left(z^{\prime}, G F z^{\prime}\right) & \leq \delta_{1}\left(G F z^{\prime}, G F z^{\prime}\right) \\
& \leq c \max \left\{d_{1}\left(z^{\prime}, z^{\prime}\right), \delta_{1}\left(z^{\prime}, G F z^{\prime}\right), \delta_{2}\left(F z^{\prime}, F z^{\prime}\right)\right\} \\
& =c \delta_{2}\left(F z^{\prime}, F z^{\prime}\right) \leq c \delta_{2}\left(F z^{\prime}, F G F z^{\prime}\right) \leq c \delta_{2}\left(F G F z^{\prime}, F G F z^{\prime}\right) \\
& \leq c^{2} \max \left\{\delta_{2}\left(F z^{\prime}, F z^{\prime}\right), \delta_{2}\left(F z^{\prime}, F G F z^{\prime}\right), \delta_{1}\left(G F z^{\prime}, F G z^{\prime}\right)\right\} \\
& =c^{2} \delta_{2}\left(G F z^{\prime}, G F z^{\prime}\right)
\end{aligned}
$$

and so $F z^{\prime}$ is a singleton and $G F z^{\prime}=\left\{z^{\prime}\right\}$, since $c<1$. Thus,

$$
\begin{aligned}
d_{1}\left(z, z^{\prime}\right) & =\delta_{1}\left(G F z, G F z^{\prime}\right) \\
& \leq c \max \left\{d_{1}\left(z, z^{\prime}\right), \delta_{1}(z, G F z), \delta_{1}\left(z^{\prime}, G F z^{\prime}\right), \delta_{2}\left(F z, F z^{\prime}\right)\right\} \\
& =c d_{2}\left(F z, F z^{\prime}\right) .
\end{aligned}
$$

But

$$
\begin{aligned}
d_{2}\left(F z, F z^{\prime}\right) & \leq \delta_{2}\left(F G F z, F G F z^{\prime}\right) \\
& \leq c \max \left\{\delta_{2}\left(F z, F z^{\prime}\right), \delta_{2}(F z, F G F z), \delta_{2}\left(F z^{\prime}, F G F z^{\prime}\right), \delta_{1}\left(G F z, G F z^{\prime}\right)\right\} \\
& =c \max \left\{d_{2}\left(F z, F z^{\prime}\right), d_{2}(F z, F z), d_{2}\left(F z^{\prime}, F z^{\prime}\right), d_{1}\left(z, z^{\prime}\right)\right\} \\
& =c d_{1}\left(z, z^{\prime}\right)
\end{aligned}
$$

and so

$$
d_{1}\left(z, z^{\prime}\right) \leq c^{2} d_{1}\left(z, z^{\prime}\right)
$$

Since $c<1$, the uniqueness of $z$ follows.

Similarly, $w$ is the unique fixed point of $F G$. This completes the proof of the theorem. 
If we let $F$ be a single valued mapping $T$ of $X$ into $Y$ and $G$ be a single valued mapping of $Y$ into $X$, we obtain the following result given in [3].

COROLLARY 1. Let $\left(X, d_{1}\right)$ and $\left(Y, d_{2}\right)$ be complete metric spaces. If T is a continuous mapping of $X$ into $Y$, and $S$ is a mapping of $Y$ into $X$ satisfying the inequalities

$$
\begin{aligned}
& d_{1}\left(S T x, S T x^{\prime}\right) \leq c \max \left\{d_{1}\left(x, x^{\prime}\right), d_{1}(x, S T x), d_{1}\left(x^{\prime}, S T x^{\prime}\right), d_{2}\left(T x, T x^{\prime}\right)\right\}, \\
& d_{2}\left(S T y, S T y^{\prime}\right) \leq c \max \left\{d_{2}\left(y, y^{\prime}\right), d_{2}(y, T S y), d_{2}\left(y^{\prime}, T S y^{\prime}\right), d_{1}\left(S y, S y^{\prime}\right)\right\}
\end{aligned}
$$

for all $x, x^{\prime}$ in $X$ and $y, y^{\prime}$ in $Y$, where $0 \leq c<1$, then $S T$ has a unique fixed point $z$ in $X$ and TS has a unique fixed point $w$ in $Y$. Further $T z=w$ and $S w=z$.

THEOREM 2. Let $\left(X, d_{1}\right)$ and $\left(Y, d_{2}\right)$ be compact metric spaces. If $F$ is a continuous mapping of $X$ into $B(Y)$, and $G$ is a continuous mapping of $Y$ into $B(X)$ satisfying the inequalities

$$
\begin{aligned}
& \delta_{1}\left(G F x, G F x^{\prime}\right)<\max \left\{d_{1}\left(x, x^{\prime}\right), \delta_{1}(x, G F x), \delta_{1}\left(x^{\prime}, G F x^{\prime}\right), \delta_{2}\left(F x, F x^{\prime}\right)\right\}, \\
& \delta_{2}\left(F G y, F G y^{\prime}\right)<\max \left\{d_{2}\left(y, y^{\prime}\right), \delta_{2}\left(y^{\prime}, F G y\right), \delta_{2}\left(y^{\prime}, F G y^{\prime}\right), \delta_{1}\left(G y, G y^{\prime}\right)\right\}
\end{aligned}
$$

for all $x, x^{\prime}$ in $X$ and $y, y^{\prime}$ in $Y$ for which the right-hand sides of the inequalities are positive. Then $F G$ has a unique fixed point $z$ in $X$ and GF has a unique fixed point $w$ in $Y$. Further $F G z=\{z\}$ and $G F w=\{w\}$.

Proof. Let us denote the right-hand side of inequalities (20) by $h\left(x, x^{\prime}\right)$ and $k\left(y, y^{\prime}\right)$, respectively. First of all suppose that $h\left(x, x^{\prime}\right) \neq 0$ for all $x, x^{\prime} \in X$ and $k\left(y, y^{\prime}\right) \neq 0$ for all $y, y^{\prime} \in Y$. Define the real-valued function $f\left(x, x^{\prime}\right)$ on $X^{2}$ by

$$
f\left(x, x^{\prime}\right)=\frac{\delta_{1}\left(G F x, G F x^{\prime}\right)}{h\left(x, x^{\prime}\right)} .
$$

Then if $\left\{\left(x_{n}, x_{n}^{\prime}\right)\right\}$ is an arbitrary sequence in $X^{2}$ converning to $\left(x, x^{\prime}\right)$, it follows from the lemma and the continuity of $F$ and $G$ the sequence $\left\{f\left(x_{n}, x_{n}^{\prime}\right)\right\}$ converges to $f\left(x, x^{\prime}\right)$. The function $f$ is therefore a continuous function defined on the compact metric space $X^{2}$ and so achieves its maximum value $c_{1}$. Because of inequality (9), $c_{1}<1$ and so

$$
\delta_{1}\left(G F x, G F x^{\prime}\right) \leq c_{1} \max \left\{d_{1}\left(x, x^{\prime}\right), \delta(x, G F x), \delta_{1}\left(x^{\prime}, G F x^{\prime}\right), \delta_{2}\left(F x, F x^{\prime}\right)\right\}
$$

for all $x, x^{\prime}$ in $X$.

Similarly, there exists $c_{2}<1$ such that

$$
\delta_{2}\left(F G y, F G y^{\prime}\right) \leq c_{2} \max \left\{d_{2}\left(y, y^{\prime}\right), \delta_{2}(y, F G y), \delta_{2}\left(y^{\prime}, F G y^{\prime}\right), \delta_{1}\left(G y, G y^{\prime}\right)\right\}
$$

for all $y, y^{\prime}$ in $Y$. It follows that the conditions of Theorem 2 are satisfied with $c=$ $\max \left\{c_{1}, c_{2}\right\}$ and, so, once again there exist $z$ in $X$ and $w$ in $Y$ such that $G F z=\{z\}$ and $F G w=\{w\}$.

Now, suppose that $h\left(x, x^{\prime}\right)=0$ for some $x, x^{\prime}$ in $X$. Then $G F x=G F x^{\prime}=\{x\}=\left\{x^{\prime}\right\}$ is a singleton $\{z\}$ and then $F z$ is a singleton $\{w\}$. It follows that $z$ is a fixed point of 
$G F$ and $G F z=\{z\}$. Further,

$$
F G w=F G F z=F z=\{w\}
$$

and so $w$ is a fixed point of $F G$.

It follows similarly that if $k\left(y, y^{\prime}\right)=0$ for some $y, y^{\prime}$ in $Y$, then again $G F$ has a fixed point $z$ and $F G$ has a fixed point $w$.

Now let us suppose that $G F$ has a second fixed point $z^{\prime}$ in $X$ so that $z^{\prime}$ is in $G F z^{\prime}$. Then on using inequalities (20), we have, on assuming that $\delta_{2}\left(F z^{\prime}, F z^{\prime}\right) \neq 0$,

$$
\begin{aligned}
\delta_{1}\left(z^{\prime}, G F z^{\prime}\right) & \leq \delta_{1}\left(G F z^{\prime}, G F z^{\prime}\right) \\
& <\max \left\{d_{1}\left(z^{\prime}, z^{\prime}\right), \delta_{1}\left(z^{\prime}, G F z^{\prime}\right), \delta_{2}\left(F z^{\prime}, F z^{\prime}\right)\right\} \\
& =\delta_{2}\left(F z^{\prime}, F z^{\prime}\right) \leq \delta_{2}\left(F z^{\prime}, F G F z^{\prime}\right) \leq \delta_{2}\left(F G F z^{\prime}, F G F z^{\prime}\right) \\
& <\max \left\{\delta_{2}\left(F z^{\prime}, F z^{\prime}\right), \delta_{2}\left(F z^{\prime}, F G F z^{\prime}\right), \delta_{1}\left(G F z^{\prime}, F G z^{\prime}\right)\right\} \\
& =c^{2} \delta_{2}\left(G F z^{\prime}, G F z^{\prime}\right)
\end{aligned}
$$

a contradiction and so $F z^{\prime}$ is a singleton and $G F z^{\prime}=\left\{z^{\prime}\right\}$. Thus, if $z \neq z^{\prime}$

$$
\begin{aligned}
d_{1}\left(z, z^{\prime}\right) & =\delta_{1}\left(G F z, G F z^{\prime}\right) \\
& <\max \left\{d_{1}\left(z, z^{\prime}\right), \delta_{1}(z, G F z), \delta_{1}\left(z^{\prime}, G F z^{\prime}\right), \delta_{2}\left(F z, F z^{\prime}\right)\right\} \\
& =d_{2}\left(F z, F z^{\prime}\right) .
\end{aligned}
$$

But if $F z \neq F z^{\prime}$, we have

$$
\begin{aligned}
d_{2}\left(F z, F z^{\prime}\right) & \leq \delta_{2}\left(F G F z, F G F z^{\prime}\right) \\
& <\max \left\{\delta_{2}\left(F z, F z^{\prime}\right), \delta_{2}(F z, F G F z), \delta_{2}\left(F z^{\prime}, F G F z^{\prime}\right), \delta_{1}\left(G F z, G F z^{\prime}\right)\right\} \\
& =\max \left\{\delta_{2}\left(F z, F z^{\prime}\right), d_{2}(F z, F z), d_{2}\left(F z^{\prime}, F z^{\prime}\right), d_{1}\left(z, z^{\prime}\right)\right\} \\
& =d_{1}\left(z, z^{\prime}\right)
\end{aligned}
$$

and so

$$
d_{1}\left(z, z^{\prime}\right)<d_{1}\left(z, z^{\prime}\right)
$$

a contradiction. The uniqueness of $z$ follows.

Similarly, $w$ is the unique fixed point of $F G$. This completes the proof of the theorem.

If we let $F$ be a single valued mapping $T$ of $X$ into $Y$ and $G$ be a single valued mapping of $Y$ into $X$, we obtain the following result given in [3].

COROLlary 2. Let $\left(X, d_{1}\right)$ and $\left(Y, d_{2}\right)$ be compact metric spaces. If $T$ is a continuous mapping of $Y$ into $X$, and $S$ is a continuous mapping of $Y$ into $X$ satisfying the inequalities

$$
\begin{aligned}
& d_{1}\left(S T x, S T x^{\prime}\right)<\max \left\{d_{1}\left(x, x^{\prime}\right), d_{1}(x, S T x), d_{1}\left(x^{\prime}, S T x^{\prime}\right), d_{2}\left(T x, T x^{\prime}\right)\right\}, \\
& d_{2}\left(T S y, T S y^{\prime}\right)<\max \left\{d_{2}\left(y, y^{\prime}\right), d_{2}(y, T S y), d_{2}\left(y^{\prime}, T S y^{\prime}\right), d_{1}\left(S y, S y^{\prime}\right)\right\}
\end{aligned}
$$


for all $x, x^{\prime}$ in $X$ and $y, y^{\prime}$ in $Y$ for which the right-hand sides of the inequalities are positive, then $S T$ has a fixed point $z$ in $X$ and TS has a unique fixed point $w$ in $Y$. Further, $T z=w$ and $S w=z$.

\section{REFERENCES}

[1] B. Fisher, Common fixed points of mappings and set-valued mappings, Rostock. Math. Kolloq. (1981), no. 18, 69-77. MR 83e:54041. Zbl 479.54025.

[2] _ Set-valued mappings on metric spaces, Fund. Math. 112 (1981), no. 2, 141-145. MR 82h:54074. Zbl 456.54009.

[3] _ Related fixed points on two metric spaces, Math. Sem. Notes Kobe Univ. 10 (1982), no. 1, 17-26. MR 83k:54050. Zbl 501.54032.

FiSHER: DEPARTMENT OF MATHEMATICS AND COMPUTER SCIENCE, UNIVERSITY OF LEICESTER, LEICESTER, LE1 7RH, ENGLAND

E-mail address: fbr@1e.ac.uk

TÜRKoḠLU: DePaRtMent of MATHematics, KirikKale UniVersity, 71450 YahşıHAN, KIRIKKALE, TURKEY

E-mail address: turkoglu@sinanoglu.kku.edu.tr 


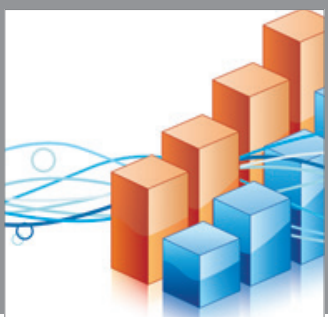

Advances in

Operations Research

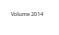

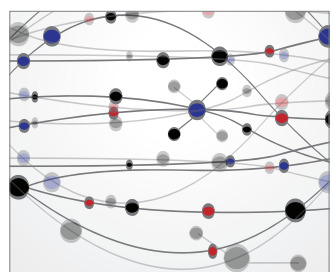

\section{The Scientific} World Journal
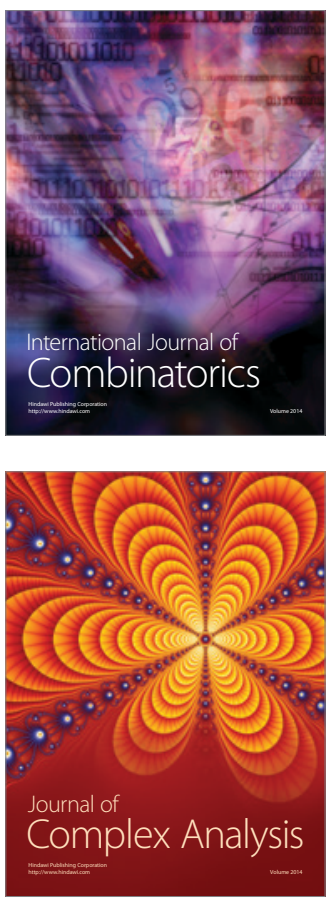

International Journal of

Mathematics and

Mathematical

Sciences
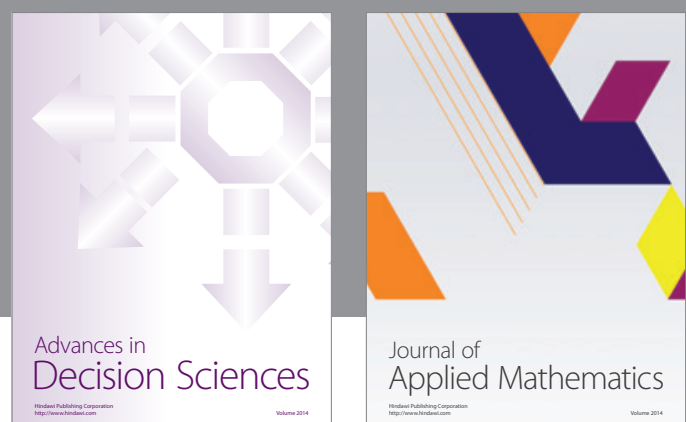

Journal of

Applied Mathematics
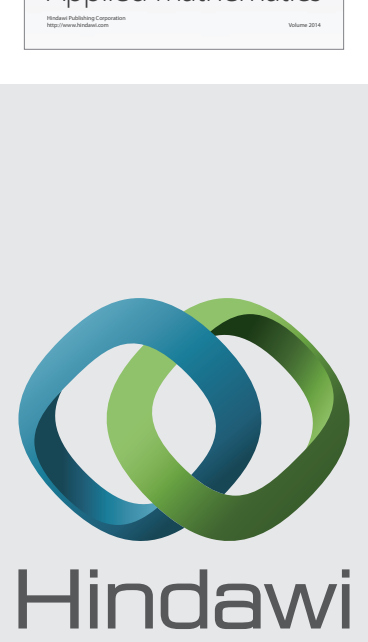

Submit your manuscripts at http://www.hindawi.com
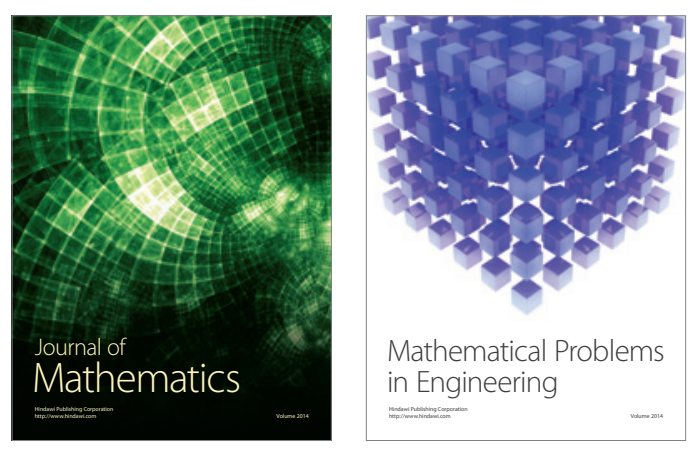

Mathematical Problems in Engineering
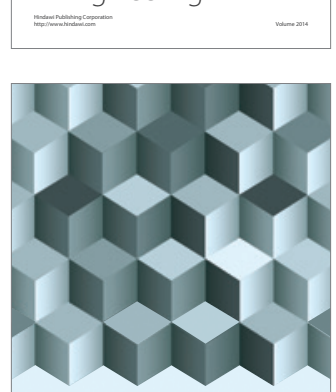

Journal of

Function Spaces
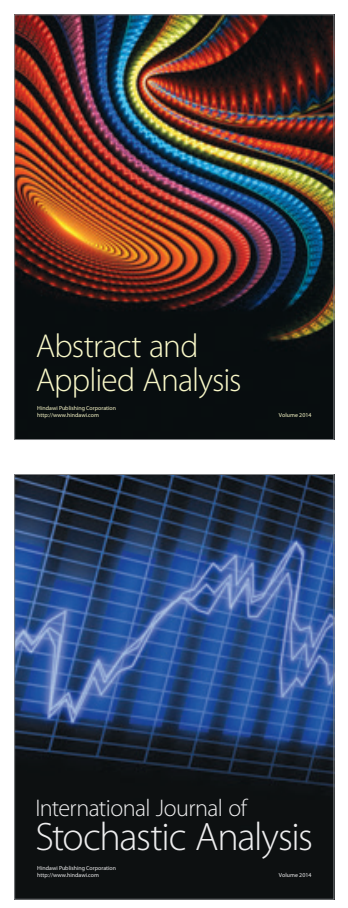

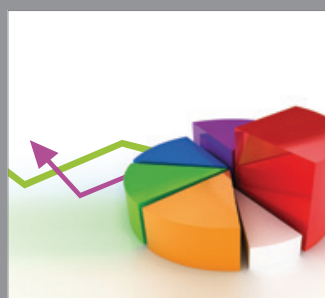

ournal of

Probability and Statistics

Promensencen
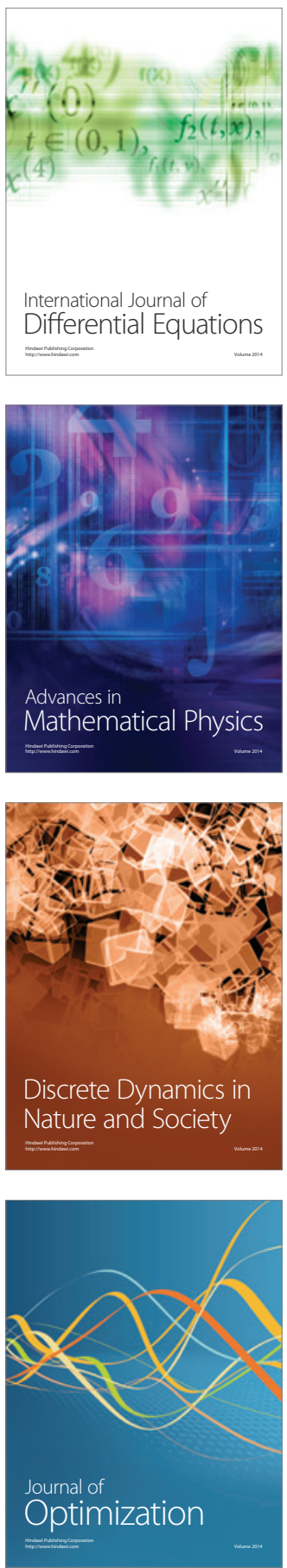